\title{
Microstructural changes upon annealing in ODS-strengthened ultrafine grained ferritic steel
}

\author{
Zbigniew Oksiuta $\cdot$ Pawel Kozikowski $\cdot$ \\ Malgorzata Lewandowska • Masato Ohnuma • \\ Koppoju Suresh · Krzysztof J. Kurzydlowski
}

Received: 30 November 2012/ Accepted: 20 February 2013/Published online: 7 March 2013

(c) The Author(s) 2013. This article is published with open access at Springerlink.com

\begin{abstract}
In this study, the stability of grain size and oxide nanoparticles in the ODS steel upon annealing at high temperature $\left(650-1350{ }^{\circ} \mathrm{C}\right)$ has been evaluated. The ODS Fe-Cr-W-Ti- $\mathrm{Y}_{2} \mathrm{O}_{3}$ steel has been manufactured by powder metallurgy, consolidated by hot isostatic pressing and processed by hydrostatic extrusion. Such a processing brings about ultrafine grain structure reinforced with oxide nanoparticles (few nm in diameter) and results in superior mechanical properties. The stability of nano-oxides has been analyzed by small angle X-ray scattering together with transmission electron microscopy. The results obtained revealed excellent thermal stability of ultrafine grained ODS ferritic steel, which was attributed to the resistance of oxides against coarsening.
\end{abstract}

\section{Introduction}

Ultrafine grained materials are attractive for advanced structural applications due to their high strength combined with acceptable ductility [1-3]. Their high strength results

Z. Oksiuta

Mechanical Department, Bialystok University of Technology,

Wiejska 45c, 15-351 Białystok, Poland

P. Kozikowski $(\bowtie) \cdot$ M. Lewandowska · K. J. Kurzydlowski

Faculty of Materials Science and Engineering, Warsaw

University of Technology, Woloska 141, 02-507 Warsaw,

Poland

e-mail: p.kozikowski@inmat.pw.edu.pl

P. Kozikowski $\cdot$ M. Ohnuma $\cdot$ K. Suresh

National Institute for Materials Science, 1-2-1 Sengen,

Tsukuba 305-0047, Japan from small grain sizes as described by the Hall-Petch relationship. However, the small grain size implies inherent, relatively low thermal stability $[4,5]$ due to high energy accumulated primarily in the form of grain boundaries. In order to preserve high mechanical strength at elevated temperatures, migration of the grain boundaries need to be restricted. One of the strategies in this respect is to pin grain boundaries with dispersed oxides. Such a strategy was successfully used in microcrystalline oxide dispersion-strengthened ODS nickel or cobalt-based alloys $[6,7]$ intended for aircraft engines.

In the present work, we adopt ODS strategy to stabilize ultrafine grained structure of a reduced activation ferritic (ODS RAF) steel for fusion applications. Recent results show a beneficial effect of oxide nanoparticles on the high temperature thermal, creep, and irradiation resistance $[8,9]$. However, this effect is observed only if these particles are sufficiently small and well dispersed in the ferritic matrix. On the other hand, during exposure to high temperature/creep, they may undergo coarsening, which results in a deterioration of the mechanical properties. Thus, the knowledge on high temperature changes in the microstructure of such steels has a fundamental meaning to determining the operating temperature window of the future fusion power reactors.

Direct observations of nanoparticles' coarsening are challenging as they require high resolution microscopy. On the other hand, statistically meaningful data can be obtained also indirectly with small angle X-ray scattering (SAXS) which is far from being a standard technique of characterization methods. These two methods were employed here to evaluate microstructural changes upon annealing in ODS strengthened ultrafine grained ferritic steel with a special emphasis on coarsening of oxide nanoparticles and its influence on the grain size stability. 


\section{Experimental procedure}

Oxide dispersion strengthened-reduced activation ferritic $\mathrm{Fe}-14 \mathrm{Cr}-2 \mathrm{~W}-0.3 \mathrm{Ti}-0.3 \mathrm{Y}_{2} \mathrm{O}_{3}$ steel was manufactured from a pre-alloyed argon-atomized $\mathrm{Fe}-14 \mathrm{Cr}-2 \mathrm{~W}-0.3 \mathrm{Ti}$ powder. Mechanical alloying (MA) was carried out in an attritor ball mill in hydrogen atmosphere. The metal powders were MA with $0.3 \% \quad \mathrm{Y}_{2} \mathrm{O}_{3}$ nanoparticles (size from 20 to $40 \mathrm{~nm}$ ). The resulting mixture was degassed and HIPped at $1150{ }^{\circ} \mathrm{C}$ under the pressure of $200 \mathrm{MPa}$ for $3 \mathrm{~h}$.

In order to improve the fracture impact properties of as-HIPped specimens were subjected to thermomechanical treatment by a Hydrostatic Extrusion, HE, at $900{ }^{\circ} \mathrm{C}$ under a pressure of $\sim 1 \mathrm{GPa}$ with a reduction ratio of 4.1 . Such a processing results in reduced grain size and residual porosity, bringing about improved strength and impact properties [10]. Extruded samples were annealed at temperature ranging from 650 up to $1350{ }^{\circ} \mathrm{C}$, for $1 \mathrm{~h}$ in $\operatorname{argon}$ atmosphere. After annealing, they were cooled slowly with a furnace to ambient temperature.

Chemical composition of the ODS steel after consolidation is summarized in Table 1. It can be noted that the excess oxygen content $\left(E_{x}\right)$, calculated from equation proposed in Ref. [11] does not exceed $0.1 \%$.

The microstructure of $14 \mathrm{Cr}$ ODS specimens at different steps of the manufacturing route was characterized by means of TEM. Microhardness was measured with a Vickers diamond pyramid under a load of $0.98 \mathrm{~N}$ for $15 \mathrm{~s}$. Chemical analyses were performed by gas chromatography-mass spectrometry method as well as LECO TC-436 and LECO IR-412 analyzers.

The SAXS measurements were performed using two systems at the National Institute for Materials Science (NIMS). For the low- $q$-region from 0.07 to $1 \mathrm{~nm}^{-1}$, a Bruker Nano-star was used with $\mathrm{Cr} \mathrm{K} \alpha(\lambda=0.22 \mathrm{~nm})$ radiation. For the high-q-region from 0.2 to $7 \mathrm{~nm}^{-1}$, Rigaku Nano-viewer was used with Mo $\mathrm{K} \alpha(\lambda=0.07 \mathrm{~nm})$. In order to obtain a good transmission rate the ODS samples with a size of $200 \mu \mathrm{m}$ were mechanically ground to $30 \mu \mathrm{m}$ in thickness. In the analyses, it was assumed that oxide nanoparticles are $\mathrm{Y}_{2} \mathrm{Ti}_{2} \mathrm{O}_{7}$ (pyrochlore), as indicated by TEM-EDS analysis reported in Ref. [12, 13]. The scattering intensity, $I(q)$, can be described by the following equation:

$I(q)=\Delta \rho^{2} d_{N} \int_{0}^{\infty} N(r)[V(r) F(q, r)]^{2} \mathrm{~d} r$ where $\Delta \rho$ is difference between scattering length density between the particles and the matrix; $\mathrm{dn}$ and $V(r)$ are number density and volume of the particles, respectively. $F(q, r)$ is the form factor of the particles scatterers and $N(r)$ is the normalized particles size distribution function. Based on the TEM observation particles have been assumed to have spherical shape, therefore their form factor equals:

$F(q, r)=\frac{3[\sin (q r)-(q r) \cos (q r)]}{(q r)^{3}}$

The normalized particles size distribution function with radius $r$, was assumed to have a log-normal distribution. Having assumed the stoichiometry of the particles, form factor and size distribution function one can extract the volume fraction and number density from the SAXS data by Eq. (1).

It should be noted that SAXS provides global quantitative data on the size distribution of the precipitates as well as their volume fraction whereas the microscopy a local information on the particles' structure and their spatial distribution.

\section{Results}

SAXS measurements

Typical SAXS profiles for ODS steel samples after different thermomechanical treatments are shown in Fig. 1. For the samples annealed up to $1250{ }^{\circ} \mathrm{C}$, the scattering is the same. This implies no visible changes in oxide particles. For the sample annealed at $1350{ }^{\circ} \mathrm{C}$ there is a shift in the curve in the scattering vector $q$ range of $0.2-3 \mathrm{~nm}^{-1}$. This indicates diffusional changes in size (coarsening) of nano-yttria taking place upon annealing at such a temperature.

The coarsening of oxide nanoparticles at $1350{ }^{\circ} \mathrm{C}$ is confirmed by the data in Fig. 2, which presents particle size distribution and their average diameters. By curve fitting to the experimental data, a sharp and narrow $(0-6 \mathrm{~nm})$ size distribution of the nanoparticles was revealed overlapping with a second broad one $(0-14 \mathrm{~nm})$. From these, one can see that oxide particles are stable up to $1250{ }^{\circ} \mathrm{C}$ in terms of the size distribution and the mean value (diameter of $2.6 \mathrm{~nm}$ ). It should be also noted that the increase in the average particle diameter after annealing at $1350{ }^{\circ} \mathrm{C}$ is

Table 1 Chemical composition of the RAF ODS $14 \mathrm{Cr}$ steel after the consolidation by HE

\begin{tabular}{lllllllllllll}
\hline Element & $\mathrm{Fe}$ & $\mathrm{Cr}$ & $\mathrm{W}$ & $\mathrm{Ti}$ & $\mathrm{Mn}$ & $\mathrm{C}$ & $\mathrm{Al}$ & $\mathrm{Y}$ & $\mathrm{O}$ & $\mathrm{N}$ & $\mathrm{H}$ & $\mathrm{E}_{\mathrm{x}}^{*}$ \\
\hline $\mathrm{wt} \%$ & 83.1 & 13.6 & 1.92 & 0.33 & 0.38 & 0.06 & 0.15 & 0.26 & 0.17 & 0.018 & $27.4(\mathrm{ppm})$ & 0.0998 \\
\hline
\end{tabular}

$* E_{x}=T_{O x}-0.27 \times Y$, where; $T_{O x}$ and $Y$ is the total oxygen and yttrium content (in wt $\%$ ) 


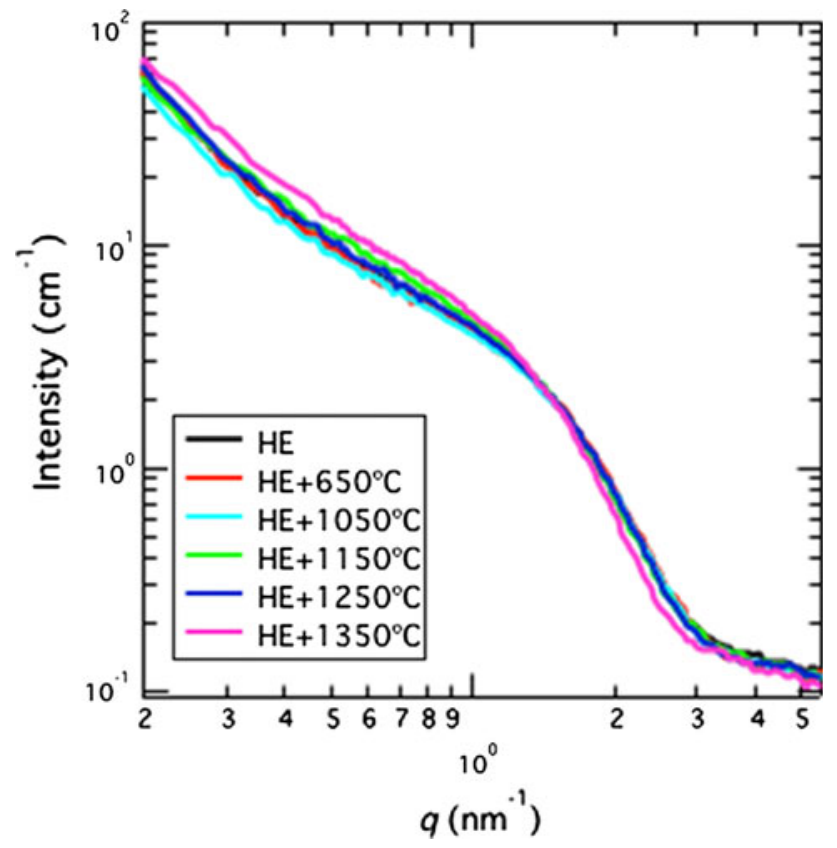

Fig. 1 SAXS profile of ODS steel after HE and HE + various HT

rather moderate, from 2.6 to $2.9 \mathrm{~nm}$. On the other hand, such a small change in the diameter implies a twofold decrease in the number density at a constant volume fraction (see Fig. 3).

From the data obtained in SAXS measurements, the volume fraction and number density can also be determined, as illustrated in Fig. 3. The results show that the volume fraction does not change upon annealing and stays within the experimental error margin. On the other hand, the number density, which is equal to $9.2 \times 10^{17} \mathrm{~cm}^{-3}$ for HE sample, drops to $5.8 \times 10^{17} \mathrm{~cm}^{-3}$ after annealing at $1350{ }^{\circ} \mathrm{C}$.

\section{TEM observations}

TEM observations revealed the presence of very small yttria nanoparticles homogenously distributed in the matrix (see Fig. 4). Their average diameter, measured from TEM images with a computer image analyses, was found to be equal to about $3.0 \mathrm{~nm}$ which is in reasonable agreement with SAXS data. Semi-quantitative analyses of the TEM images of as-HE ODS steel, exemplified by the micrograph presented in Fig. 5a, suggest that more than $65 \%$ of the nano-oxide particles have the size smaller than $5 \mathrm{~nm}$.

It can be further noted that the annealing at $1050{ }^{\circ} \mathrm{C}$ does not cause any significant changes in the size and spatial distribution of the nanoparticles (see Fig. 4b). At the highest testing temperature, however, significant coarsening is observed as shown in Fig. 4c. This is in a good accordance with results reported by Miller et al. [12] who reported that the oxide nanoparticles were extremely resistant to coarsening during isothermal aging at $1300{ }^{\circ} \mathrm{C}$. The coarsening of the nano-particles at $1350{ }^{\circ} \mathrm{C}$ is confirmed by the histogram of the particle size distribution presented in Fig. 5b.

\section{Discussion}

Coarsening mechanism of oxide nanoparticles

The results presented clearly show good thermal stability of oxides' nanoparticles up to annealing temperature of $1250{ }^{\circ} \mathrm{C}$ and their moderate growth at higher annealing temperatures. In order to have an insight into the kinetics of coarsening the results obtained in this study should be analyzed in conjunction with the one reported in the previous work [14], obtained for a long-term annealing at $750{ }^{\circ} \mathrm{C}$. At this temperature, the particle size changes from $2.8 \pm 0.8$ to $6.8 \pm 1.6 \mathrm{~nm}$ with a coarsening kinetics that can be described by the formula given by Lapin et al. [15]:

$d_{p}=K \cdot t^{m}$,

where $K$ is the material constant of the diffusion coefficient and $m$ is the time exponent. These results, presented in the
Fig. 2 Particle size distribution a and their average diameter b after $\mathrm{HE}$ and $\mathrm{HE}+$ various annealing conditions

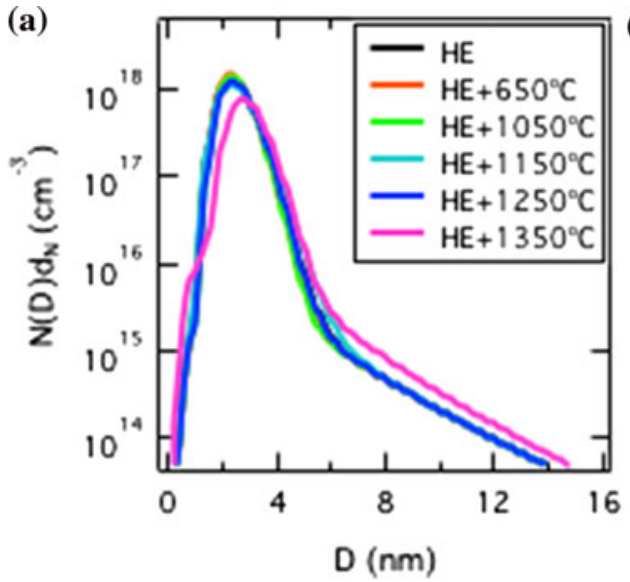

(b)

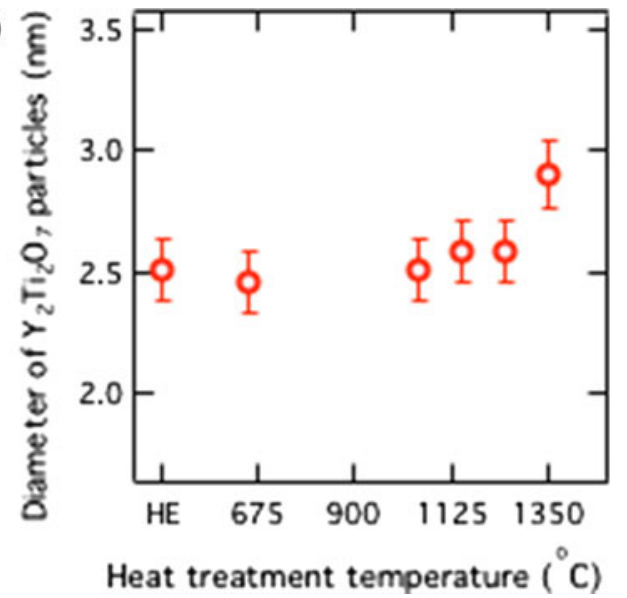


Fig. 3 Volume fraction a and number density $\mathbf{b}$ of oxide nanoparticles in ODS steel after $\mathrm{HE}$, and $\mathrm{HE}+$ various annealing conditions
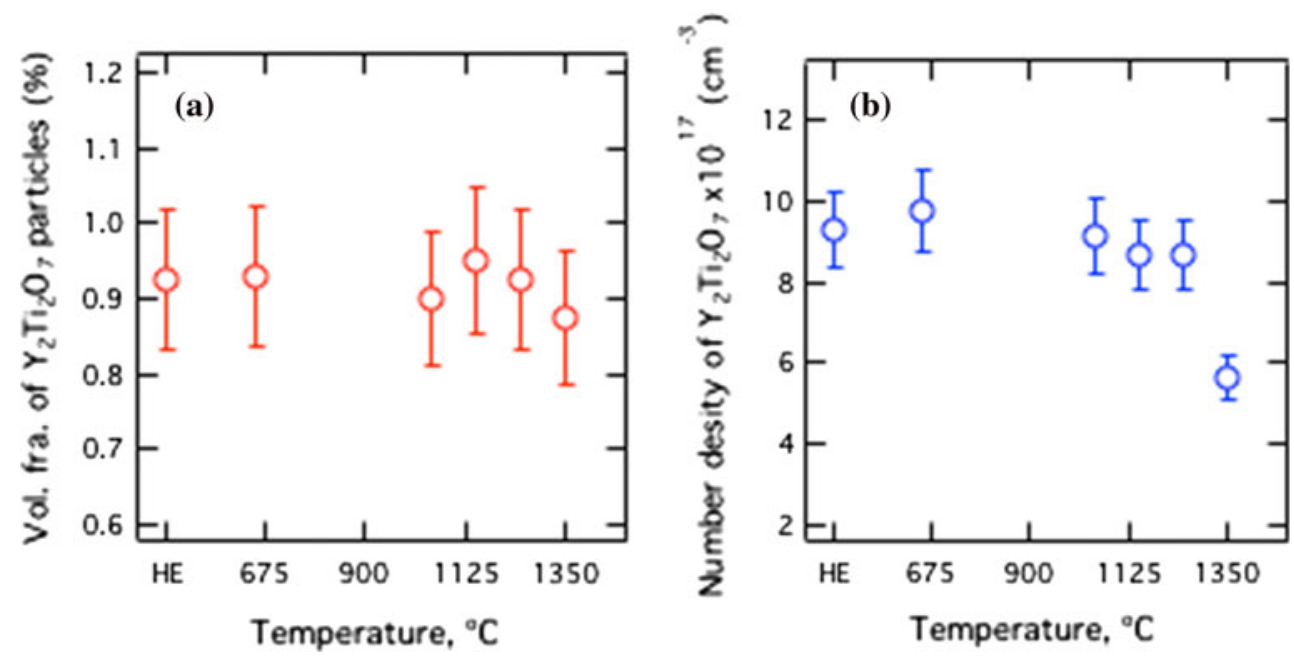


Fig. 4 TEM images of the nano-particles after: a HE, b $\mathrm{HE}+$ annealing at $1050{ }^{\circ} \mathrm{C}$ and $\mathbf{c} \mathrm{HE}+$ annealing at $1350{ }^{\circ} \mathrm{C}$

$\log -\log$ coordinates (Fig. 6a), provide exponent $m$ for oxides' nanoparticles being equal to $\sim 0.3$, which indicates that boundary diffusion plays a significant role in coarsening of the nanoparticles. Thus, the activation energy of this process can be calculated from the Arrhenius relationship, as suggested in [16]:

$d^{3}-d_{0}^{3}=K \cdot t \cdot \exp (-Q / R T)$
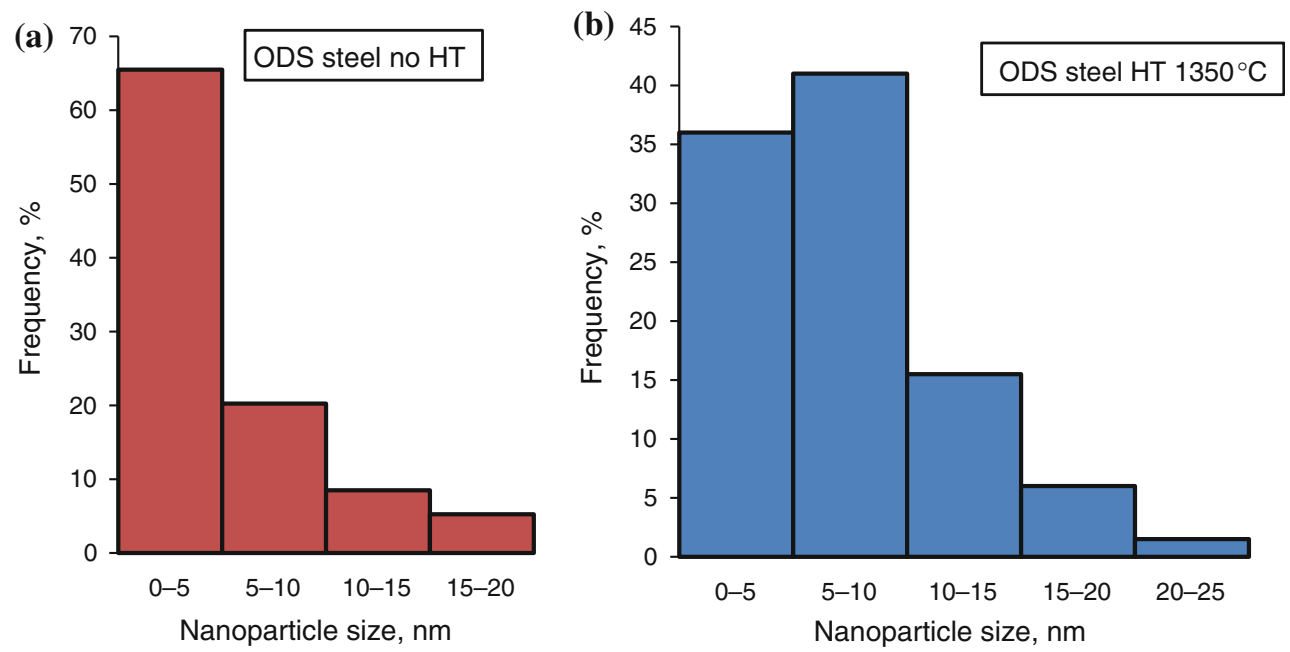

Fig. 5 Histogram of the nano-particles size after: a $\mathrm{HE}$ and $\mathbf{b} \mathrm{HE}$ and annealing at $1350{ }^{\circ} \mathrm{C}$ for $1 \mathrm{~h}$ in argon 
Fig. 6 a Time exponent calculation and $\mathbf{b}$ Arrhenius relation showing the dependence of mean nanoparticle size as a function of inverse temperature
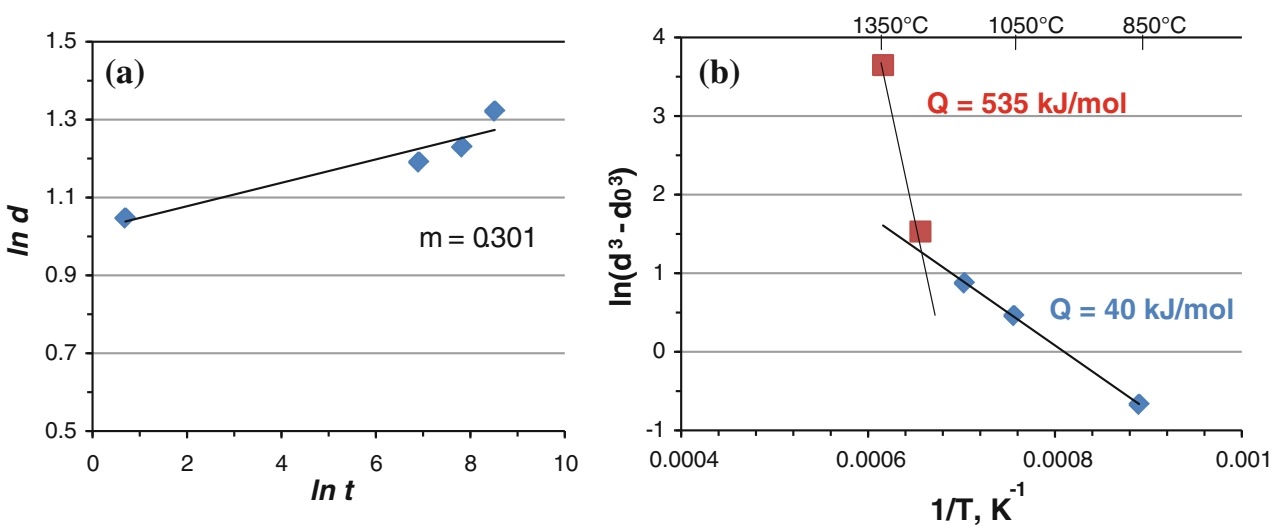

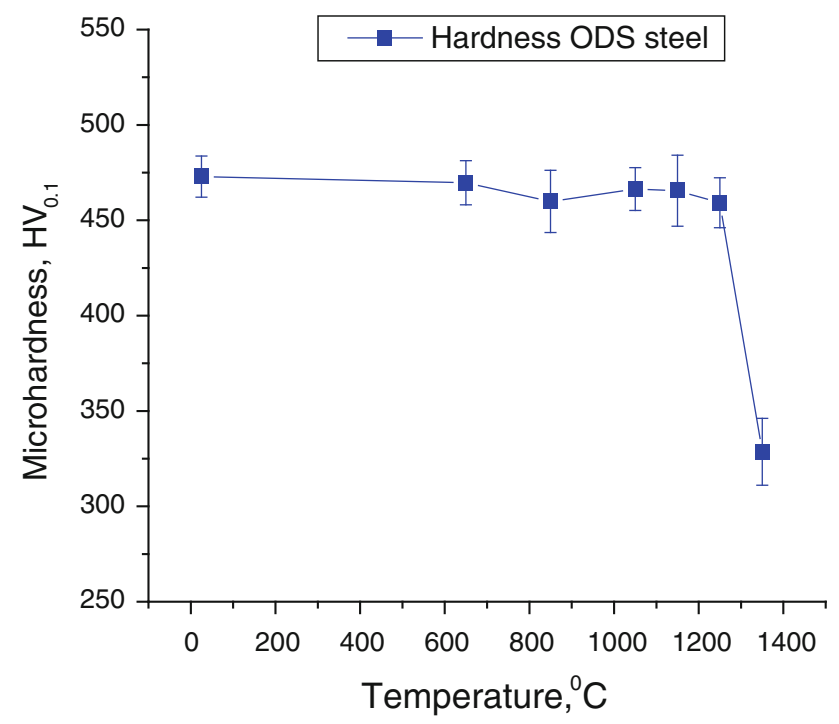

Fig. 7 Microhardness as a function of the annealing temperature

where $R$ is the gas constant, $T$ is the absolute temperature, $Q$ is the activation energy of process, $K$ is the material constant, and $d_{0}$ and $d$ are the sizes of nanoparticles at the initial and final stages of process, respectively. This equation (4) can be reformulated to: $\ln \left(d^{3}-d_{0}^{3}\right)=$ $\ln (K \cdot t)-Q / R T$, and after plotting as $\ln \left(d^{3}-d_{0}^{3}\right)$ vs. $1 / T$ the activation energy of nanoparticle coarsening can be estimated as illustrated in Fig. 6b.

Interestingly, two different slopes of the curve in Fig. 6b can be distinguished below $1250{ }^{\circ} \mathrm{C}$ and above this temperature. The activation energy for these two temperature ranges is 40 and $535 \mathrm{~kJ} / \mathrm{mol}$, respectively. This may suggest two different mechanisms of nanoparticle coarsening. At lower temperatures, the activation energy is somewhat close to the activation energy of diffusion of interstitial atoms (e.g., $\mathrm{C}, \mathrm{O}$ ) in iron lattice. However, there is a kinetic limit for particle growth due to the unavailability of $\mathrm{Y}$ atoms which movement is restricted at such low temperatures. At higher temperature, the measured activation energy can be correlated with the activation energy of diffusion of solute substitutional atoms (e.g., Y, Ti) in iron, which is $\sim 400 \mathrm{~kJ} / \mathrm{mol}[17,18]$. As a result relatively fast, diffusion-controlled particle growth takes place.

Grain size and hardness stability

Excellent thermal stability of oxide nanoparticles imparts a very good thermal stability of the ultrafine grained ODS ferritic steel as reflected by microhardness changes
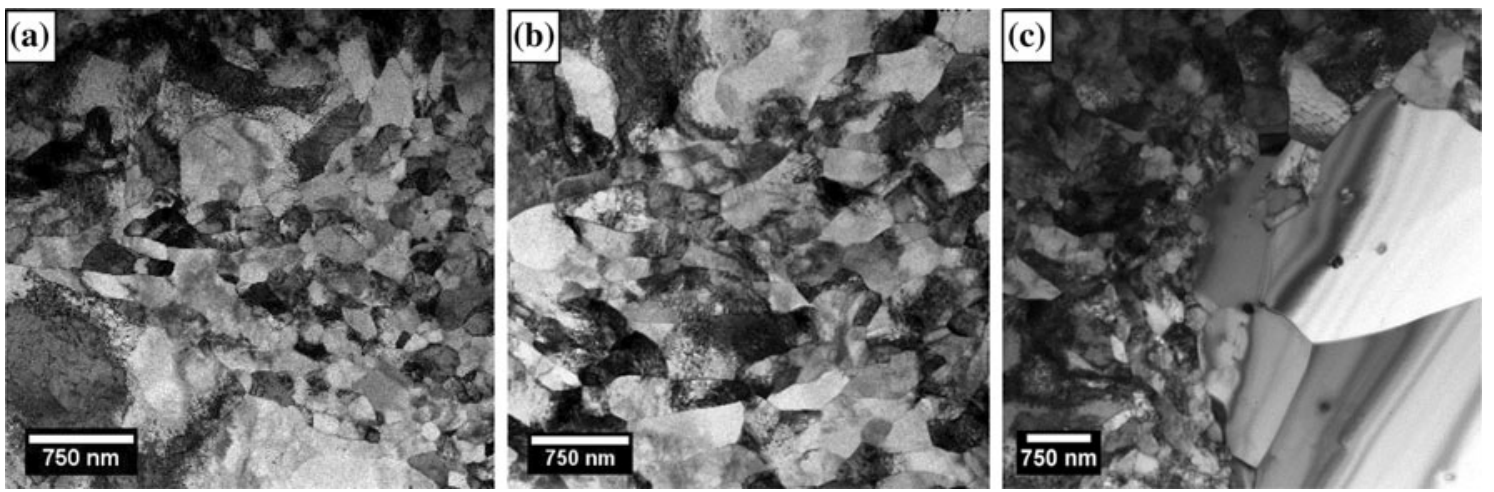

Fig. 8 TEM images of the RAF ODS steel after HIPping and $\mathrm{HE}$ at $900{ }^{\circ} \mathrm{C}$ : a after $\mathrm{HE}$, b $\mathrm{HE}+$ annealing at $1050{ }^{\circ} \mathrm{C}$, and $\mathbf{c} \mathrm{HE}+\mathrm{HT}$ annealing at $1350{ }^{\circ} \mathrm{C}$ 
(Fig. 7). Up to annealing at $1250{ }^{\circ} \mathrm{C}$, no significant changes in the microhardness of the specimens were observed. After annealing at the temperature of $1350{ }^{\circ} \mathrm{C}$, the microhardness drops from 460 to $325 \mathrm{HV}_{0.1}$ (approximately by $30 \%$ ).

Representative TEM images of the ODS ferritic steel after $\mathrm{HE}$ and annealing at various temperatures are shown in Fig. 8. As-HE ODS sample exhibits an inhomogeneous bimodal grain structure (Fig. 8a) with smaller grains of about $250 \mathrm{~nm}$ in equivalent diameter. The bigger grains span up to a few microns. Post $\mathrm{HE}$ annealing at $1150{ }^{\circ} \mathrm{C}$ (Fig. 8b) preserves the microstructure of the ODS steel almost unaffected. However, a significant increase in the volume fraction of bigger grains (the diameter of which is of the order of a few microns) was observed after annealing at the highest temperature of $1350{ }^{\circ} \mathrm{C}$ (see Fig. 8c).

It should be emphasized that the coarsening proceeds via the bigger grains coarsening, whereas the smaller grains remain almost unaffected. This observation can be explained by the interactions of the grain boundaries in ferritic matrix with the nanoparticles present in the material [19]. Especially, Y-Ti-O nanoparticles are expected to suppress grain growth imparting a very good thermal stability of the ODS ferritic steels [11, 12].

\section{Conclusions}

The results obtained in the present study allow to draw the following conclusions:

1. Oxide dispersion strengthening enables excellent thermal stability of an ultrafine grained ferritic steel. The microstructure and mechanical properties remain stable up to annealing at $1250{ }^{\circ} \mathrm{C}$ for $1 \mathrm{~h}$.

2. The major factor influencing the stability of ODS steel is high resistance of oxide nanoparticles upon annealing. They remain stable in terms or size and size distribution up to annealing at $1250{ }^{\circ} \mathrm{C}$ for $1 \mathrm{~h}$.

3. The loss of microstructural stability at higher annealing temperature is related to the coarsening of oxide nanoparticles occurring at annealing temperature higher that $1300{ }^{\circ} \mathrm{C}$.
Acknowledgements This work was carried out within the framework of the European Fusion Development Agreement. It was supported by grants from the European Communities within the EURATOM-IPPLM and EURATOM- Confédération Suisse Technical Program and the Polish Ministry of Science and Higher Education.

Open Access This article is distributed under the terms of the Creative Commons Attribution License which permits any use, distribution, and reproduction in any medium, provided the original author(s) and the source are credited.

\section{References}

1. Mishra A, Martin M, Thadhani N, Kad B, Kenik E, Meyers M (2008) Acta Mater 56:2770

2. Valiev RZ, Islamgaliev RK, Alexandrov IV (2000) Prog Mater Sci 45:103

3. Lewandowska M, Kurzydlowski KJ (2008) J Mater Sci 43:7299. doi:10.1007/s10853-008-2810-Z

4. Jiang H, Zhu Y, Butt D, Alexandrov I, Lowe T (2000) Mater Sci Eng A 290:128

5. Lewandowska M, Kurzydłowski KJ (2005) Mater Charact 55:395

6. Whittenberger JD (1977) Metall Trans A 8:1155

7. Zhang L, Qu XH, He XB, Din R, Qin ML, Zhu HM (2012) J Alloy Compd 512:39

8. Kishimoto H, Alinger MJ, Odette GR, Yamamoto T (2004) J Nucl Mater 329-333:369

9. Hayashi T, Sarosi PM, Schneibel JH, Mills MJ (2008) Acta Mater 56:1407

10. Oksiuta Z, Lewandowska M, Kurzydłowski KJ, Baluc N (2010) Phys Stat Sol A 207:1128

11. Kaito T, Ohtsuka S, Inoue M, Asayama T, Uwaba T, Mizuta S, Ukai S, Furukawa T, Ito C, Kagota E, Kitamura R, Aoyama T, Inoue T (2009) J Nucl Mater 386-388:294

12. Miller MK, Hoelzer DT, Kenik EA, Russell KF (2005) Intermetallics 13:387

13. Yamashita S, Akasaka N, Ohnuki S (2004) J Nucl Mater 329-333:377

14. Oksiuta Z, Lewandowska M, Kurzydlowski K.J (2013) Mechanical properties and thermal stability of ODS RAF steels. Mechanics of Materials, after revision

15. Lapin J, Vano A (2004) Scr Mater 50:571

16. Li H, Song X, Wang Y, Chen G (2009) J Iron Steel Res Int 16:81

17. Alinger MJ, Odette GR, Hoelzer DT (2004) J Nucl Mater 329-333:382

18. Chiu Y, Lin C (2012) J Power Sour 198:149

19. Ukai S, Okuda T, Fujiwara M, Kobayashi T, Mizuta S, Nakashima H (2002) J Nucl Sci Technol 39:872 